\title{
Seasonal photoadaptation and diatom dynamics in temperate waters
}

\author{
Niall Broekhuizen ${ }^{1, *}$, Mark Hadfield ${ }^{2}$, Arnold H. Taylor ${ }^{3}$ \\ ${ }^{1}$ National Institute of Water \& Atmospheric Research Ltd, PO Box 11-115, Gate 10, Silverdale Road, Hamilton, New Zealand \\ ${ }^{2}$ National Institute of Water \& Atmospheric Research LId, PO Box 14-901, 301 Evans Bay Parade, Greta Point, Wellington, \\ New Zealand \\ ${ }^{3}$ Plymouth Marine Laboratory, Prospect Place, West Hoe, Plymouth PL1 3DH, United Kingdom
}

\begin{abstract}
Using a fully depth-resolved nutrient-phytoplankton model we investigate the influence that photoadaptive responses may have upan the seasonal dynamics of diatoms in the subtropical waters to the east of New Zealand. The wintertime diatom standing stocks can differ by up to 2 orders of magnitude depending upon the form of photoadaptive response assumed. As a consequence of this difference in wintertime stocks, the timing of the spring bloom varies by almost 1 mo. The spring bloom is terminated by $\mathrm{N}$ limitation rather than by Si limitation.
\end{abstract}

KEY WORDS: Phytoplankton - Overwintering Modelling Photoadaptation

\section{INTRODUCTION}

Recent technological and computational advances have brought about a renewed interest in the experimental and theoretical study of algal photoadaptation, but much of this work has focused upon short-term (time scale of hours to days) photoadaptation such as might arise as a result of diurnal light cycles and vertical transport through the water column (e.g. Lande \& Lewis 1989, Fisher et al. 1996). One of the most frequently recorded short-term photoadaptive responses is of enhanced chl: $\mathrm{C}$ ratios under conditions of low light intensity (Verity 1981, Pan et al. 1996). This results in an increased initial slope $(\alpha)$ of the classical (carbon weight-specific) photosynthesis-irradiance curve. Over the longer term, it is reasonable to expect that seasonal variations in the daily pattern of surface ir radiance, water-column turbidity and depth of mixing would induce the average alga to be adapted to a lower irradiance in the winter than it would be in the summer Indeed, whilst open to alternative interpretations, there are field observations of changes in community-leve] photosynthetic characteristics which are consistent with this explanation (e.g. Frenette et al. 1996).

•E-mail: n.broekhuizen@niwa.cri.nz
Models which have explicitly addressed the kinetics of photoadaptation and its implications for short-term mixed-layer production (e.g. Woods \& Onken 1982, Kamykowski et al. 1994) have not included any representation of nutrient limitation of algal growth. Consequently, they are of limited value for making realistic, longer-term simulations. Conversely, models which have included representations of nutrient dynamics have usually not included any representation of photoadaptation. Furthermore, most havê focussed upon summertime dynamics in coastal waters, yet photoadaptation might be expected to be most important to species persistence during the winter, when the photoperiod is short, the sun is low in the sky (reducing the instantaneous incident radiation), and the depth of mixing is greatest. Where wintertime dynamics have been accurately simulated the models have usually been of coastal waters and 'open-system' incorporating either a boundary condition (e.g. Ross et al. 1993) or a 'nudging function' (e.g. Moisan \& Hofmann 1996). Both boundary conditions and 'nudging functions' will tend to prescribe a model's dynamics. Consequently, any intrinsic tendency of the (closed-system) model to perform poorly during some part of the year may be masked. Three 'oceanic' nutrient-phytoplankton models which have made detailed comparisons between 
simulated wintertime algal dynamics and field are: Fasham et al. (1990), Doney et al. (1996), and Hadfield \& Sharples (1996). The former model is only able to accurately simulate the winter stocks at the expense of overpredicting the summer stocks. Doney et al. (1996) incorporated a photoadaptive description, but their model still tends to slightly underestimate the depthintegrated winter algal stocks. Hadfield \& Sharples (1996) presented a model of algal dynamics in the deep waters to the east of New Zealand's South Island. They were able to simulate the mid-winter (July) chlorophyll concentrations remarkably accurately; however, they used an unusually low light-saturation coefficient and had no data against which to compare the performance of their model during other months of the year.

In this paper we ask the question: can seasonal photoadaptation significantly influence the dynamics of diatoms in oceanic mixed layers? In particular we focus upon the subtropical waters to the east of New Zealand's North Island, and compare our simulations with data gathered at several times of the year. We use the phrase 'seasonal photoadaptation' to describe changes in the photosynthetic characteristics of an algal population which are manifest over time scales of weeks to months. Such changes might simply be longer-term expressions of the well documented shortterm (hours to days), physiologically mediated photoadaptive response. Alternatively, it is conceivable that seasonal photoadaptation might reflect genotypic changes associated with with seasonally varying selection pressures.

\section{THE MODEL}

The initial model explicitly represents the depthresolved dissolved inorganic $N$, dissolved reactive sili-

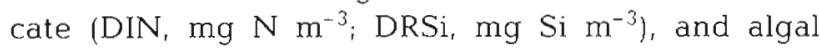
(diatom) biomass $\left(B, \mathrm{mg} \mathrm{C} \mathrm{m}^{-3}\right)$ concentrations. Ultimately, the model will be extended into a full planktonic foodweb model. With a view to minimising the complexity of this final model, we have aimed to keep the representation of algal dynamics as simple as possible. Consequently, the $\mathrm{N}: \mathrm{C}$ and $\mathrm{Si}$ C ratios $\left(\rho_{\mathrm{N}}, \rho_{\mathrm{S}_{\mathrm{I}}}\right)$ of the algae are assumed to be fixed. Furthermore, because we are focusing upon seasonal rather than diurnal photoadaptation, we represent the response by means of an explicit function in preference to modelling the kinetics of photoadaptation per se. We will explore several phenomenological models of seasonal photoadaptation, but in every case we ignore diurnal photoadaptation.

The standard advection-dispersion equation is augmented with expressions relating to phytoplankton growth:

$$
\begin{aligned}
& \frac{\partial B}{\partial t}+\frac{\partial}{\partial z}\left(\omega(z) B-k(t, z) \frac{\partial B}{\partial z}\right)= \\
& \left(\mu_{C}(t, z)-m_{C}(z)-I_{C}-e_{C}(z)-d\right] B(z) \\
& \frac{\partial \mathrm{DIN}}{\partial t}+\frac{\partial}{\partial z}\left(-k(t, z) \frac{\partial \mathrm{DIN}}{\partial z}\right)=-\left[\mu_{N}(t, z)-e_{\mathrm{N}}(z)\right] B(z)(2) \\
& \frac{\partial \mathrm{DRSi}}{\partial t}+\frac{\partial}{\partial z}\left(-k(t, z) \frac{\partial \mathrm{DRSi}}{\partial z}\right)=-\left[\mu_{\mathrm{Si}}(t, z)-e_{\mathrm{S}}(z)\right] B(z)(3)
\end{aligned}
$$

in which $t$ denotes time (d), $z$ denotes depth (m), w represents the local sinking velocity $\left(\mathrm{m} \mathrm{d}^{-1}\right), k$ represents the local vertical dispersion coefficient $\left(\mathrm{m}^{2} \mathrm{~d}^{-1}\right)$, and $\mu_{(\mathrm{C}, \mathrm{N} \text {.Si) }}$ represent the local, daily average phytoplankton gross carbon, nitrogen and silicon uptake rates $\left(d^{-1}\right)$. The carbon respiration, leakage and excretion rates $\left(\mathrm{d}^{-1}\right)$ are respectively denoted by $m_{C}, l_{C}$ and $e_{C}$. The nitrogen and silicate excretion rates are cenoted by $e_{N}$ and $e_{S_{1}}$, whilst $d$ denotes the mortality rate $\left(d^{-1}\right)$. We assume that there is no respiratory or leakage loss of nitrogen or silicon, however these elements may be 'actively excreted' (see below). Dead algae are assumed to pass into a detrital compartment. In the simulations presented here this represents a permanent sink term because we have assumed that the detritus does not remineralise prior to sinking out of the bottom of the water column. This is certainly justified for silicon given its low remineralisation rate (Tréguer et al. 1989) and the high sinking speeds of diatomaceous detritus (Smayda 1970). The assumption is less valid for $\mathrm{N}$ but we have found that our results are insensitive to this assumption (see 'Discussion').

The instantaneous depth-specific gross photosynthetic rate is assumed to equal the corresponding daily average gross photosynthetic rate (Eq. 4). This is calculated from the time integral of the Smith (1936) model of photosynthesis assuming a half-sinusoid diumal pattern of irradiance (McBride 1992). Whilst the integral is exact in McBride (1992), it is only approximate in this case because the water temperature is not constant.

$$
\begin{aligned}
& \mu_{C}(t, z)= \\
& \frac{2 P_{m} \phi(t, 0) \theta[T(t, z)]}{\pi} \sin ^{-1}\left(\frac{I_{\text {noon }}(t, z)}{\sqrt{\left(\frac{P_{\mathrm{m}} \theta[T(t, z)]}{\alpha(t, z)}\right)^{2}+I_{\text {noon }}^{2}(t, z)}}\right)
\end{aligned}
$$

Where $P_{\mathrm{m}}$ (mg $\mathrm{C} \mathrm{mg}^{-1} \mathrm{C} \mathrm{d}^{-1}$ ) denotes the carbonweight-specific maximum photosynthetic rate and $\alpha(t, z)\left(\mathrm{d}^{-1}\left[\mu \mathrm{E} \mathrm{m} \mathrm{m}^{-2} \mathrm{~s}^{-1}\right]^{-1}\right)$ determines the initial slope of the $P$-I curve at depth $z . I_{\text {noon }}\left(\mu \mathrm{E} \mathrm{m}^{-2} \mathrm{~s}^{-1}\right)$ denotes the maximum (solar noon) irradiance immediately below the water surface, and $\phi(t, 0)$ represents the photoperiod fraction (hours of daylight/24). Both are assumed to 
vary sinusoidally throughout the year, being maximal on December 21 (Southern Hemisphere summer solstice). $\theta[T(t, z)]$ is a temperature dependence function:

$$
\theta[T(t, z)]=\theta_{P_{m}}{ }^{01\left[T(t, z)-T_{P_{n}}\right]}
$$

in which $\hat{\theta}_{P \mathrm{~m}}$ is the snape factor, whilst $I$ and $T_{P \mathrm{~m}}$ respectively denote the local instantantaneous and reference temperatures.

The corresponding nitrogen and silicate uptake rates $\left(\mu_{N}, \mu_{S_{1}}\right)$ are given by Monod-type equations

$$
\mu_{\mathrm{N}}(t, z)=P_{\mathrm{m}} \rho_{\mathrm{N}} \theta[T(t, z)] \frac{\operatorname{DIN}(z)}{k_{N}+\operatorname{DIN}(z)}
$$

and

$$
\mu_{S_{1}}(t, z)=P_{\mathrm{m}} \rho_{S_{1}} \theta[T(t, z)] \frac{\operatorname{DRSi}(z)}{k_{S_{1}}+\operatorname{DRSi}(z)}
$$

in which $k_{\mathrm{N}}$ and $k_{\mathrm{Si}}$ are half-saturation coefficients.

Following Langdon (1993), respiratory losses $\left(m_{C}\right.$, $\mathrm{d}^{-1}$ ) are assumed to stem from 2 sources-a basal, temperature independent term, and an 'activity' term which is proportional to the gross photosynthetic rate and influenced by temperature:

$$
m_{C}(z)=m_{b} B(z)+m_{a} \theta_{m a}^{0.1\left[T(t, z)-T_{m a}{ }^{0}\right.} B(z) \mu_{C}(z)
$$

where $m_{b}\left(\mathrm{~d}^{-1}\right)$ and $m_{a}$ (dimensionless) denote the weight-specific and gross photosynthetic rate specific respiratory costs respectively, $\theta_{m a}$ determines the temperature response and $T_{m a}$ is a reference temperature. In actively growing algae we assume that the respiration debt is paid solely by burning carbohydrate; there can be a net excretion of DIN (and DRSi) only when the gross (carbon) respiration rate exceeds the gross carbon fixation rate. In this case, the net excess of the 2 non-limiting elements is excreted in order to ensure that the algal N:C and Si:C ratios are held constant. The excretion rates are therefore given by:

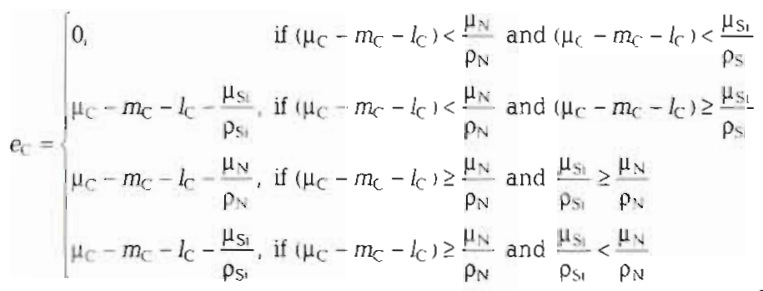

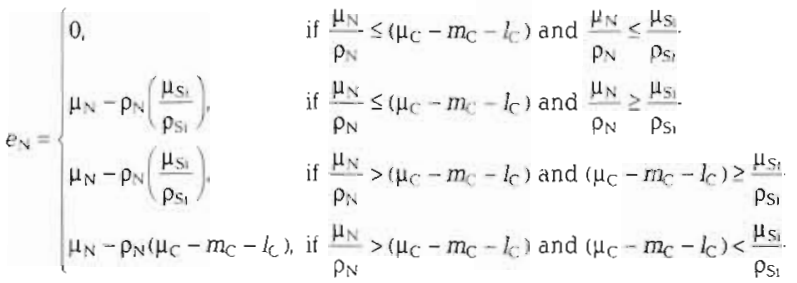

$$
\begin{aligned}
& \text { (0, } \quad \text { if } \frac{\mu_{S i}}{\rho_{S t}} \leqslant\left(\mu_{C}-m_{C}-k\right) \text { and } \frac{\mu_{S_{1}}}{\rho_{S i}} \leq \frac{\mu_{N}}{\rho_{N}} \\
& e_{S_{1}}=\left\{\mu_{S_{1}}-\rho_{S_{1}}\left(\frac{\mu_{N}}{\rho_{N}}\right), \quad \text { if } \frac{\mu_{S_{1}}}{\rho_{S 1}} \subseteq\left(\mu_{C}-m_{C}-H_{C}\right) \text { and } \frac{\mu_{S_{1}}}{\rho_{S 1}} \geq \frac{\mu_{N}}{\rho_{N}}\right. \\
& \left(\mu_{S,}-\rho_{S,}\left(\frac{\mu_{N}}{\rho_{N}}\right), \quad \text { if } \frac{\mu_{S t}}{\rho_{S}}>\left(\mu_{C}-m_{C}-b\right) \text { and }\left(\mu_{C}-m_{C}-l_{C}\right) \geq \frac{p^{2} N}{\rho_{N}}\right. \\
& \mu_{S t}-\rho_{S t}\left(\mu_{C}-m_{C}-l_{C}\right)_{i} \text { if } \frac{\mu_{S i}}{\rho_{S t}}>\left(\mu_{C}-m_{C}-l_{C}\right) \text { and }\left(\mu_{C}-m_{C}-l_{C}\right)<\frac{\mu_{S A}}{\rho_{N}}
\end{aligned}
$$

Mortality is assumed to operate as a temperature dependent first-order process:

$$
d[T(t, z)]=d_{0} \theta_{d}{ }^{01(z+z)-T_{d} !}
$$

$d_{0}\left(\mathrm{~d}^{-1}\right)$ denotes the weight-specilic mortality rate at temperature $T_{d}$, whilst $\theta_{d}$ determines the temperature dependence of the mortality rate. The mortality term embraces all causes of death-grazing, pathogens, senescence, etc., but sinking losses are represented as a separate, explicit term. There are comparatively few estimates of the influence which temperature has upon gross photosynthesis (cf. net growith), respiration and death, and we have followed common practice and assumed that photosynthesis, respiration and mortality all have the same temperature dependence (exponential, base 2).

The local sinking velocity is determined by the sum of 2 terms: a passive sinking speed, and a buoyancymediated 'swimming speed'. There is mounting evidence that diatoms are able to regulate their buoyancy, at least when nutrients and energy are plentiful (Waite et al. 1992). We assume that the passive sinking speed of a diatom is $4 \mathrm{~m} \mathrm{~d}^{-1}$ (a conservatue assumption), but so long as they are fixing more carbon than they require to meet metabolic expenditure they are able to reduce their sinking speed to $0.4 \mathrm{~m} \mathrm{~d}^{-1}$. They 'choose' to do so only if the vertical gradient of net growth rate is negative. Whilst we acknowledge that buoyancy regulation demands an expenditure of energy we make no explicit representation of this term in the metabolic budget.

The existence of photoadaptatim has been recognized for several decades, but it is only more recently that the kinetics of the physiological processes underlying the photoadaptive response have been studied. The most commonly reported type of photoadaptation is an increase in the (carbon-werght-specific) initial slope of the P-I curve (Fisher et al. 1996, Pan et al. 1996) at low ambient light intensities, but there are also some reports that this may alson increase when the photoperiod is short (Sakshaug et al. 1991). We have investigated the consequences of several photoadaptive models. The simplest, baseline model is that there is no photoadaptation (non-adaptive model):

$$
\alpha(t, z)=\text { constant. }
$$


We examine 2 further models for the seasonal photoadaptive state which are based upon the explicit solutions for the depth-specific equilibrium photoadaptive state presented by Lande \& Lewis (1989) (Eq 13b). They were able to derive an explicit expression for the depth-specific photoadaptive state which takes into account the 'disruptive' impact of vertical mixing by assuming: (1) that the eddy dispersion coefficient is constant throught the water column, and across time (2) a log-linear relationship between the light intensity and equilibrium photoadaptive state, (3) first order photoadaptation kinetics, and (4) an infinitely deep water column.

$$
\begin{aligned}
\alpha(t, z)= & c+m \log _{\mathrm{e}}\left(\frac{2 \phi(t, 0) I_{\text {noon }}(t, 0)}{\pi}\right) \\
& +(-m \bar{\eta}) z+(-m \bar{\eta}), \frac{\bar{K}}{\gamma} \exp \left\{\frac{-z}{\sqrt{\frac{\bar{K}}{\gamma}}}\right\}
\end{aligned}
$$

where $\gamma$ is the first order photoadaptive rate $\left(\mathrm{d}^{-1}\right)$, whilst $c$ and $m$ are the intercept and coefficient of an empirical equilibrium relationship between photoadaptive state and $\log$ (irradiance). $\bar{\eta}$ and $\bar{K}$ respectively denote the effective water-column light altenuation $\left(\mathrm{m}^{-1}\right)$ and vertical mixing $\left(\mathrm{m}^{2} \mathrm{~d}^{-1}\right)$ coefficients. The original expression upon which Eq. (13b) is based assumes that light attenuation is depth independent (Lande \& Lewis 1989). In reality, and in our model, this assumption is invalid close to the water suriace because red light is attenuated very much more rapidly than green light however, below a few meters of depth the remaining PAR is approximately monochromatic ('green') and therefore attenuation becomes essentially depth independent. In our model we have divided the PAR into 'red' and 'green' components (Taylor et al. 1991), each having different background $\left(\eta_{\mid \text {bk, red }),} \eta_{\{b k, g r n\}}, \mathrm{m}^{-1}\right\}$ and algal attenuation coefficienis ( $\eta_{\text {[alg, red], }} \eta_{\mid a l g, g r n],} \mathrm{m}^{2}$ $\left.\mathrm{mg}^{-1} \mathrm{C}\right)$. When applying Eq. (13b), we have distinguished between cells above and below the thermocline. For cells above the thermocline we use the surface-to-thermocline averaged mixing and light attenuation coefficients. Below the thermocline, we use thermocline-to-water column bottom averaged values. We define the thermocline depth $[D(t), \mathrm{m}]$ operationally as the depth at which the (absolute) temperature gradient is maximal. The layer above this depth will be referred to as the mixed layer.

The empirical log-linear relationship between irradiance and equilibrium photoadaptive state on which the Lande \& Lewis (1989) analysis is based implies that the equilibrium photoadaptive state $(\alpha)$ approaches infinity as the local irradiance falls to zero, and that it can become negative for (unnaturally) high irradiances. Clearly this empirical model becomes invalid at light intensities beyond those used in the experimental work upon which it is derived (approximately 10 to $1000 \mu \mathrm{E} \mathrm{m}^{-2} \mathrm{~s}^{-1}$ ). We have made simulations using both an unconstrained version of Eq. (13b) and a version in which $\alpha$ was constrained to lie in the range $0.02<\alpha<$ 0.08 . The constrained and unconstrained models yield almost identical simulations of the diatom density at $10 \mathrm{~m}$ depth. For the remainder of this paper the reader should assume that we are referring to simulations made using the constrained form of the Lande-Lewis model unless explicit mention to the contrary is made.

Finally, we have examined a third model (which we will term the 'photoperiod model') in which the photoadaptive state is assumed to be a function of the effective photoperiod $[\phi(t)]$. This is the fraction of the day during which the light intensity exceeds a specified intensity $\left(I_{\text {sens }}, \mu \mathrm{E} \mathrm{m}^{-2} \mathrm{~s}^{-1}\right)$, cf. the solar photoperiod the period during which the surface irradiance exceeds zero). In this model the equilibrium photoadaptive state is depth independent only if the light intensity threshold is set to zero irradiance (so that effective and solar photoperiods are identical.). Seasonal changes in the solar photoperiod are likely to be slow in comparison with changes in the effective photoperiod associated with the random, day-to-day vertical displacements of algal cells, particularly in the surface layer. We therefore distinguish between cells in the mixed layer and those in the more stable sub-thermocline waters. We assume that each cell in the mixed layer will spend an average of half of its time at a depth above $0.5 D(t)$, and half between this depth and the thermocline depth. We therefore assume that the entire mixed-layer algal population modifies its photoadaptive state in response to the effective photoperiod at a depth equal to $0.5 D(t)$. Cells below the thermocline are mixed more slowly and we assume that they photoadapt to the local effective photoperiod.

Assuming that the diurnal light cycle may be described as a half sinusoid between sunrise $\left(t_{\text {rise }}\right)$ and sunset $\left(t_{\text {set }}\right)$, and using the symbol $z_{\text {eff }}$ to denote the effective depth of the cell (half thermocline, or local depth), the effective photoperiod is:

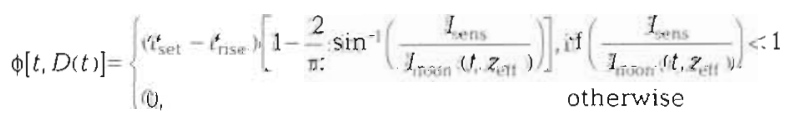

where $t_{\text {set }}$ and $t_{\text {rise }}$ denote the times of sunset and sunrise (fraction of d) and $I_{\text {noon }}(t, z)$ is the depth-specific noon irradiance $\left(\mu \mathrm{E} \mathrm{m}^{-2} \mathrm{~s}^{-1}\right.$ ). Following McBride et al. (1993), the latter is given by:

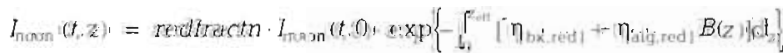

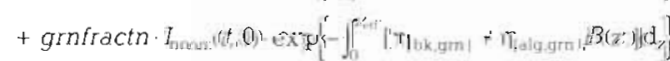


where redfractn and grnfractn denote the fractional 'red' and 'green' composition of the incoming irradiance, and $\eta$ denotes the background and algal attenuation coefficients for 'red' and 'green' light.

We assume that the photoadaptive state is a step-like fuñction of the phoivperiod:

$$
\alpha(t, z)=\alpha_{\min }+\frac{\alpha_{\text {max }}-\alpha_{\text {rnin }}}{1+\exp \left\{\alpha_{\text {slope }}\left[\phi(t, z)-\phi_{0}\right]\right\}}
$$

This function tends asymptotically towards $\alpha_{\text {min }}$ for $\phi(t, z)>\phi_{0}$ (and $\alpha_{\text {slope }}>0$ ), and towards $\alpha_{\max }$ for $\phi(t, z)<\phi_{0}$ (and $\left.\alpha_{\text {slope }}>0\right)$. The function takes the value $0.5\left(\alpha_{\min }+\right.$ $\left.\alpha_{\max }\right)$ for $\phi(t, z)=\phi_{0}$. The slope at this point is proportional to the value of $\alpha_{\text {slope }}$. The parameters of this function were chosen such that the seasonal dynamic of the mixed-layer average value of $\alpha$ would be similar to those predicted using the constrained Lande-Lewis model.

\section{NUMERICAL SOLUTION}

The partial differential equations were solved numerically after first discretizing them upon an Eulerian grid and adopting a 'control volume' approach (McBride et al. 1993). The depth of the control volume around each node increased by a factor of 1,055 per node with increasing depth. This resolution was inherited from the hydrodynamic model which provides the temperature and vertical mixing coefficients which drive this biological model. In the hydrodynamic model, the ratio of 1.055 was chosen so as to minimise the number of equations to be solved without compromising accuracy. The surfacemost control volume has a thickness of $4 \mathrm{~m}$. We used a total of 39 nodes, which places the bottom-most node at a depth of $498.8 \mathrm{~m}$. The control volume about this latter node has a thickness of approximately $30.5 \mathrm{~m}$. The air-sea interface is assumed to be closed, whilst we applied an absorbing lower boundary condition for the diatoms, and specified time-invariant DIN and DRSi concentrations at the lower interface of the bottom-most control volume. The system of coupled ordinary differential equations was solved using an explicit, forward in time (Euler) scheme (thereby avoiding the problems associated with non-linearity which manifest themselves in implicit schemes). A time step of 0.001 of a day was used. This was sufficiently small to maintain both stability and accuracy despite the occasionally very high vertical mixing rates. Preliminary simulations were made in order to ensure that mass was properly conserved by the simulation model.

The physical characteristics of the water column are driven by means of time series of (daily averaged) depth-resolved vertical dispersion coefficients and temperatures. These were derived from a hydrodynamic simulation model adapted from Hadfield \& Sharples (1996) applied to the subtropical waters to the east of New Zealand (latitude $40.5^{\circ} \mathrm{S}$, longitude $179.5^{\circ} \mathrm{E}$ ). The hydrodynamic model is run separately from the plankton model but on the same vertical grid. The model parameterises vertical mixing using the turbulence closure scheme of Gaspar et al. (1990). Wind stirring is driven by the surface momentum flux, which is estimated from wind speed measurements at a nearby island station (Hadfield 1996), adjusted by a factor of 1.52 to allow for land-sea differences. The time-average temperature profile in the ocean is taken from the World Ocean Atlas 1994 (Levitus et al. 1994) and the surface boundary condition for temperature is taken from a weekly analysis of satellite and in situ observations (Reynolds \& Smith 1994). The model is able to reproduce the observed mean seasonal cycle in mixed-layer depth accurately.

Initial conditions are derived from measurements of the characteristics of subtropical water at 2 stations to the north of Chatham Rise in June 1993. So far as possible, the biological model was parameterised from published literature (Tables 1, 2 \& 3). Two parameters were used as fitting parameters: the diatom Si:C ratio and the mortality constant. The former parameter is highly variable in nature (Brzezinski 1985). The value we have chosen $\left(0.1 \mathrm{~g} \mathrm{Si}^{-1} \mathrm{C}\right.$ ) yields a good fit to the DRSi concentrations measured following the spring bloom in subtropical waters to the east of New Zealanc. This ratio is at the lower end of the range for small oceanic diatoms (Brzezinski 1985), but Brzezinski suggests that those values are for diatoms which are soon to divide (and therefore represent near maximal values). The mortality rate was used to bring the simulated diatom carbon biomasses into (subjectively) acceptable agreement with the field data in the constrained Lande-Lewis model. It was not reestimated in order to improve the quality of the simulations in the other models. The field data are sparse, and stem from 1993 (winter measurements), and 1996 (summer measurements) only. The model was driven using the vertical mixing and temperature profiles corresponding to 1993. Given the disjunct nature of our data, we have merely used the 2 fitting parameters to bring the simulations into general agreement with the data, rather than endeavouring to formally optimise the correspondence between simulation and data.

In the non-photoadaptive simulation, the value for $\alpha$ (Eq. 13a) was chosen post hoc such that it was equal to the annual mean of the mixed-layer averaged value derived from the constrained LandeLewis model. 
Table 1. Physical characteristics in the model. The midday irradiance immediately below the water surface is given by: $I_{\text {noon }}(t, 0)$ $=h f m e a n \cdot \eta_{\text {trn }}\left[1-c l 3 \cdot(c l 1+c l 2 \times l a t)^{2}\right] \cdot\left\{1+h f a m p \cdot \cos \left[2 \pi\left(\frac{t \text {-dymaxrad }}{365}\right)\right]\right\}$. The photoperiod fraction is given by: photoperiod $=$ dylenavg $\left\{1+d y l e n a m p \cdot \cos \left[2 \pi\left(\frac{t-\text { dymaxrad }}{365}\right)\right]\right\}$ PAR: photosynthetically active radiation

\begin{tabular}{|c|c|c|c|c|}
\hline Symbol & Description & Units & Value & Source \\
\hline lat & Nominal latitude & degrees & $40.5^{\circ} \mathrm{S}$ & \\
\hline dylenavg & Annual average daylength & d & 0.5 & Assumed \\
\hline dylenamp & Half-amplitude of annual daylength cycle & - & 0.25 & Derived: Vincent et al. (1989) \\
\hline hfmean & Annual mean, midday PAR above cloud & $\mu E \mathrm{~m}^{-2} \mathrm{~s}^{-1}$ & 1587 & Derived: McBride et al. (1993) \\
\hline hfamp & $\begin{array}{l}\text { Relative half-amplitude of midday irradiance } \\
\text { cycle }\end{array}$ & $\begin{array}{l}\text { Fraction of } \\
\text { hfmean }\end{array}$ & 0.5 & Vincent et al. (1989) \\
\hline$c l 1$ & Intercept in cloud-cover-latitude relation & - & 0.149 & Vincent et al. (1989) \\
\hline$c l 2$ & Slope in cloud-cover-latitude relation & - & 0.013 & Vincent et al. (1989) \\
\hline$c / 3$ & Coeff. in cloud-cover-latitude relation & - & 0.38 & Vincent et al. (1989) \\
\hline dymaxrad & Longest day of year & Julian days & 355 & \\
\hline redfractn & 'Red' fraction in the PAR & - & 0.5 & Taylor et al. (1991) \\
\hline grafractn & 'Green' fraction in the PAR & - & 0.5 & Taylor et al. (1991) \\
\hline$\eta_{(\text {(г) }}$ & $\begin{array}{l}\text { Fractional transmission of irradiance through } \\
\text { water surface }\end{array}$ & - & 0.95 & Jerlov (1978) \\
\hline$\eta_{\mid \text {bk.red } \mid}$ & Background attenuation coeff for 'red' light & $m^{-1}$ & 0.4 & $\begin{array}{l}\text { Howard-Williams et al. (1995), } \\
\text { Bradford-Grieve et al. (1997) }\end{array}$ \\
\hline$\eta_{i b k, g r n !}$ & Background attenuation coeff. for 'green' light & $\mathrm{m}^{-1}$ & 0.085 & $\begin{array}{l}\text { Howard-Williams et al. (1995), } \\
\text { Bradford-Grieve et al. (1997) }\end{array}$ \\
\hline
\end{tabular}

Table 2. Fixed ecophysiological characteristics of the diatoms

\begin{tabular}{|c|c|c|c|c|}
\hline Symbol & Description & Units & Value & Source \\
\hline$\eta_{\text {[alg, red] }}$ & Diatom attenuation coeff. for 'red' light & $\left(\mathrm{mg} \subset \mathrm{m}^{-2}\right)^{-1}$ & 0.0004 & Taylor et al. (1991) \\
\hline$\eta_{\text {lolg, grn } 1}$ & Diatom attenuation coeff. for 'green' light & $\left(\mathrm{mgC} \mathrm{m}^{-2}\right)^{-1}$ & 0.0004 & Taylor et al. (1991) \\
\hline$\omega_{\text {sink }}$ & Sinking speed of energy-starved diatoms & $\mathrm{m} \mathrm{d}^{-\mathrm{i}}$ & 4.0 & Waite et al. (1992), Passow (1991) \\
\hline$\omega_{\text {swim }}$ & $\begin{array}{l}\text { 'Swimming' speed of energy-rich ('buoyant') } \\
\text { diatoms }\end{array}$ & $\mathrm{m} \mathrm{d}^{-1}$ & 3.6 & $\begin{array}{l}\text { Anderson \& Sweeney (1977), } \\
\text { Waite et al. (1992) }\end{array}$ \\
\hline$\rho_{N}$ & $N: C$ ratio in diatoms & $\mathrm{mg} \mathrm{mg}^{-1}$ & 0.18 & Taylor \& Joint $(1990)$ \\
\hline$\rho_{\mathrm{Si}}$ & $\mathrm{Si}: \mathrm{C}$ ratio in diatoms & $\mathrm{mg} \mathrm{mg}^{-1}$ & 0.10 & Fitted, Brzezinski (1985) \\
\hline$P_{\mathrm{in}}$ & Maximum weight-specific carbon fixation rate & $m g C \mathrm{mg}^{-1} C \mathrm{~d}^{-1}$ & 2.0 & Chan $(1980)$ \\
\hline$\theta_{p m}$ & Photosynthesis-temperature coefficient & - & 2.0 & $\begin{array}{l}\text { Steemann Nielsen \& Jørgensen } \\
\text { (1968), Yentsch \& Lee (1996), but } \\
\text { see Verity (1981) }\end{array}$ \\
\hline$T_{P \mathrm{~m}}$ & 'Standard' temperature for photosynthesis & ${ }^{\circ} \mathrm{C}$ & 20.0 & Chan $(1980)$ \\
\hline$k_{\mathrm{N}}$ & DIN uptake half-saturation coefficient & $\mathrm{mg} \mathrm{Nm}^{-3}$ & 3.0 & Caperon \& Meyer (1972) \\
\hline$k_{\mathrm{St}}$ & DRSi uptake half-saturation coefficient & $\mathrm{mg} \mathrm{Si} \mathrm{m} \mathrm{m}^{-3}$ & 30.0 & $\begin{array}{l}\text { Paasche (1973), Nelson \& Tréguer } \\
\text { (1992) }\end{array}$ \\
\hline$m_{b}$ & Basal metabolic expenditure & $\mathrm{mgCmg}^{-1} \mathrm{Cd}^{-1}$ & 0.02 & Langdon $(1993)$ \\
\hline$m_{i}$ & Growth-related respiration & - & 0.10 & Langdon (1993) \\
\hline$\theta_{m a}$ & Coeff. for temperature dependence of respiration & - & 2.0 & Verity (1981) \\
\hline$T_{m \dot{\alpha}}$ & 'Standard' temperature for respiration & ${ }^{\circ} \mathrm{C}$ & 17.0 & Verity (1981) \\
\hline$l_{c}$ & Diatom carbon leakage rate & $m g \subset \mathrm{mg}^{-1} C \mathrm{~d}^{-1}$ & 0.05 & $\begin{array}{l}\text { Malinsky-Rushansky \& Legrand } \\
\text { (1996), Mague et al. (1980) }\end{array}$ \\
\hline$d_{0}$ & Diatom mortality rate & $d^{-1}$ & 0.12 & Fitted \\
\hline$\theta_{d}$ & $Q_{10}$ for mortality & - & 2.0 & Assumed \\
\hline$T_{d}$ & Reference temperature for mortality & ${ }^{\circ} \mathrm{C}$ & 15.0 & Assumed \\
\hline
\end{tabular}


Table 3. Parameters governing the photoadaptive characteristics of the diatoms

\begin{tabular}{|c|c|c|c|c|c|}
\hline Model & Parameter & Description & Units & Value & Source \\
\hline Fixed response & & (Fixed) value of $\alpha$ & $d^{-1}\left(\mu E m^{-2} s^{-1}\right)^{-1}$ & 0.045 & $\begin{array}{l}\text { Annual, mixed-layer } \\
\text { mean from Lañde-Lewis } \\
\text { unconstrained model }\end{array}$ \\
\hline \multirow[t]{3}{*}{$\begin{array}{l}\text { Lande-Lewis } \\
\text { unconstrained }\end{array}$} & $c$ & $\begin{array}{l}\text { Constant in photoadaptive- } \\
\text { irradiance relation }\end{array}$ & $d^{-1}\left(\mu E m^{-2} s^{-1}\right)^{-1}$ & 0.0527 & Lande \& Lewis $(1989)$ \\
\hline & $m$ & $\begin{array}{l}\text { Slope in photoadaptive- } \\
\text { irradiance relation }\end{array}$ & $d^{-1}\left(\mu E m^{-2} s^{-1}\right)^{-2}$ & -0.00468 & Lande \& Lewis (1989) \\
\hline & $y$ & Rate of photoadaptation & $d^{-1}$ & $24 \times 0.568$ & Lande \& Lewis (1989) \\
\hline \multirow[t]{5}{*}{$\begin{array}{l}\text { Lande-Lewis } \\
\text { constrained }\end{array}$} & $c$ & $\begin{array}{l}\text { Constant in photoadaptive- } \\
\text { irradiance relation }\end{array}$ & $d^{-1}\left(\mu E m^{-2} s^{-1}\right)^{-1}$ & 0.0527 & Lande \& Lewis (1989) \\
\hline & $m$ & $\begin{array}{l}\text { Slope in photoadaptive-irradiance } \\
\text { relation }\end{array}$ & $d^{-1}\left(\mu E m^{-2} s^{-1}\right)^{-2}$ & -0.00468 & Lande \& Lewis (1989) \\
\hline & $\gamma$ & Rate of photoadaptation & $d^{-1}$ & $24 \times 0.568$ & Lande \& Lewis (1989) \\
\hline & $\alpha_{\min }$ & Lower limit to $\alpha$ & $d^{-1}\left(\mu E m^{-2} s^{-1}\right)^{-1}$ & 0.02 & Assumed \\
\hline & $\alpha_{\max }$ & Upper limit to $\alpha$ & $d^{-1}\left(\mu E m^{-2} s^{-1}\right)^{-1}$ & 0.08 & Assumed \\
\hline \multirow[t]{5}{*}{ Photoperiod } & $\alpha_{\text {min }}$ & Lower limit to $\alpha$ & $d^{-1}\left(\mu E m^{-2} s^{-1}\right)^{-1}$ & 0.035 & $\begin{array}{l}\text { Fitted to Lande-Lewis } \\
\text { mixed-layer average } \alpha\end{array}$ \\
\hline & $\alpha_{\max }$ & Upper limit to $\alpha$ & $\mathrm{d}^{-1}\left(\mu E \mathrm{~m}^{-2} \mathrm{~s}^{-1}\right)^{-1}$ & 0.063 & $\begin{array}{l}\text { Fitted to Lande-Lewis } \\
\text { mixed-layer average } \alpha\end{array}$ \\
\hline & $\alpha_{\text {siope }}$ & $\begin{array}{l}\text { Shape parameter in the photo- } \\
\text { adaptation-photoperiod model }\end{array}$ & $d^{-1}$ & -19.34 & $\begin{array}{l}\text { Fitted to Lande-Lewis } \\
\text { mixed-layer average } \alpha\end{array}$ \\
\hline & $\phi_{0}$ & $\begin{array}{l}\text { Effective photoperiod at which } \\
\text { algae are half-adapted }\end{array}$ & $d$ & 0.386 & $\begin{array}{l}\text { Fitted to Lande-Lewis } \\
\text { mixed-layer average } \alpha\end{array}$ \\
\hline & $I_{\text {sens }}$ & Critical light intensity & $\mu E m^{-2} s^{-1}$ & 0.1 & Assumed \\
\hline
\end{tabular}

\section{RESULTS}

The mixed layer shallows abruptly from greater than $250 \mathrm{~m}$ in early October and has a depth of approximately $50 \mathrm{~m}$ during the summer months (Fig. 1). It begins to deepen once more in April, and reaches its maximum extent in August. The midday, mid-mixedlayer light intensity exceeds $50 \mu \mathrm{E} \mathrm{m} \mathrm{m}^{-2} \mathrm{~s}^{-1}$ during late December and January (when the mixed layer is at its shallowest) but falls to little more than zero from midMay until early October (when the mixed-layer depth exceeds $100 \mathrm{~m}$ ). The corresponding mixed-layer averaged values for the photoadaptive parameter $(\alpha)$ are presented in Fig. 2. In the Lande-Lewis model they

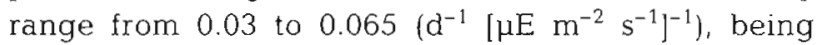
smallest around midsummer. The photoperiod model produces a similar annual cycle, though its amplitude is a little smaller. In the third model $\alpha$ was held constant at approximately the annual mixed-layer average value of the Lande-Lewis model.

Fig. $3 a-c$ presents the simulated diatom carbon, dissolved reactive silicon and dissolved inorganic nitro-

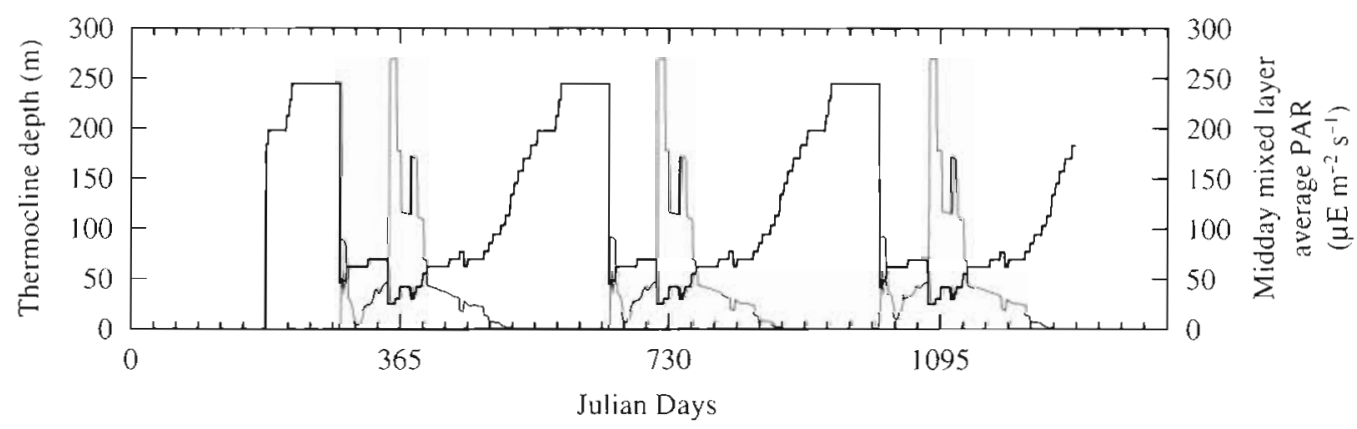

Fig. 1. Thermocline depth (depth of maximum vertical temperature gradient, thick line), and mixed-layer-averaged midday light intensity (thin line). The forcing data (temperature and mixing coefficients) are for 1993 only, but are 'recycled' in order to generate a 3 yr time series 


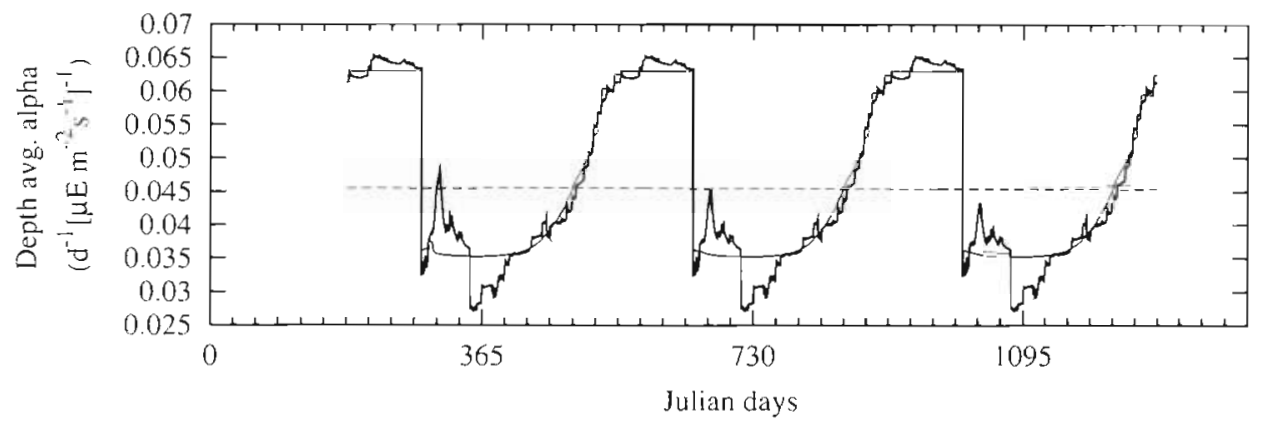

Fig. 2. Simulated mixed-layer average photoadaptive parameter $(\alpha)$. Thick line: constrained Lande \& Lewis model; thin Iine: photoperiod model ${ }_{i}$ dashed line: non-adaptive model

gen concentrations at $10 \mathrm{~m}$ depth. Also shown are the few experimental data gathered during the winter of 1993 and the summer of 1995/1996 (Bradford-Grieve et al. 1997 and NIWA unpubl. data). These data have been arranged in order by Julian day, and 'recycled' for the 3 yr simulation. The data are from measure-

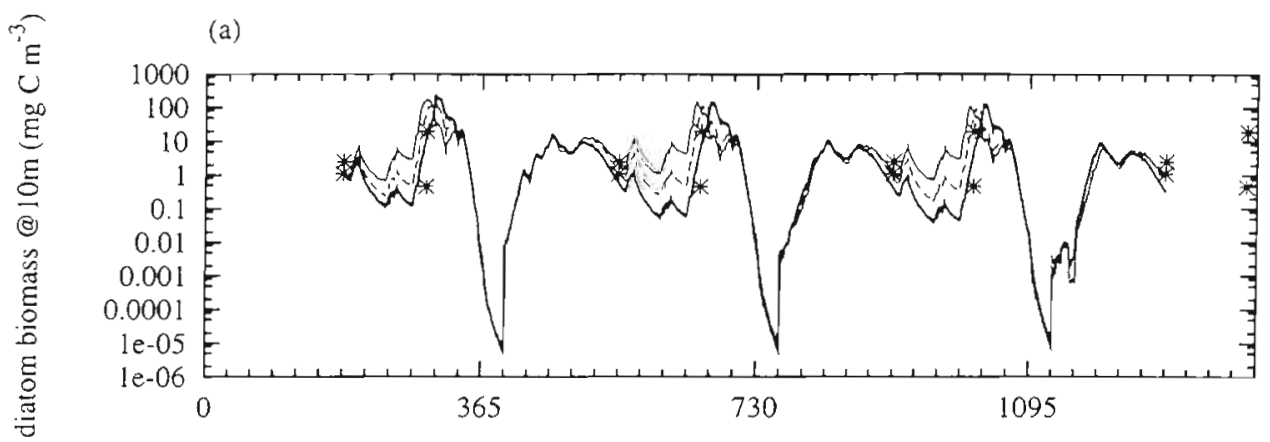

(b)

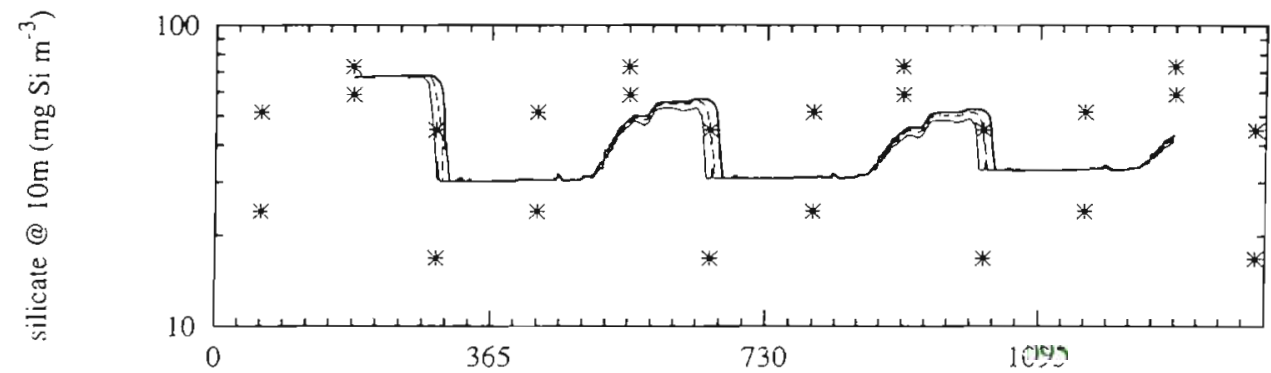

(c)

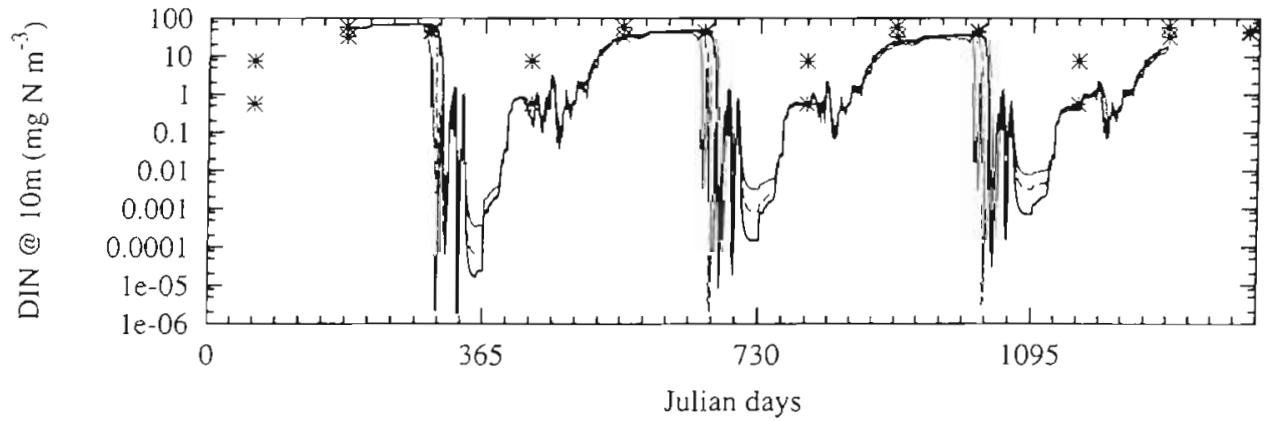

Fig. 3. Simulated (a) diatom biomass, (b) DRSi concentration and (c) DIN concentration at $10 \mathrm{~m}$ depth (thick line: constrained Lande \& Lewis model; thin line: photoperiod model; dashed line: non-adaptive model), together with corresponding field data

(*). The field data are from 1993 and 1996 field studies, and are plotted by Julian day for each year of the 3 yr simulation 
ments made at $10 \mathrm{~m}$ depth at paired stations. In the model, the diatoms are predicted to bloom in spring, shortly after the mixed-layer shallows (Fig. 1). The bloom is terminated by DIN limitation. The simulated algal biomass and DIN concentrations are in close agreement with the spring observations. Untortunately, we have no data for diatom biomass at any time during the summer months, and no nutrient data for the mid-summer period. The model predicts that DIN concentrations are maintained at very low, but varying, levels between October and February. The predicted high frequency DIN fluctuations during this period reflect sporadic, weak mixing of sub-thermocline DIN up to shallower depths. Following the bloom in spring, the diatom abundance is predicted to decline through several orders of magnitude until the end of January. At this time the thermocline depth begins to increase once more and the accompanying gradual rise of the surface layer DIN concentrations promotes a recovery of the diatom population.

Surface, wintertime nutrient concentrations are predicted to decline year upon year, indicating that the model is not at steady state, and that mixing from deep water is insufficient to fully replace the nutrients which have been removed from the surface waters by diatoms which have sedimented out of the bottom of the water column as live cells or (implicitly) as rapidly sinking (refractive) detrital matter. There is no evidence for this 'run-down' in the few data which we have, and consequently we have chosen not to run the model to a stable annual dynamic. Instead, we prefer to examine the 'transient' dynamic, which we believe to be more realistic (see 'Discussion'). In passing, we note that when the model is run to equilibrium (which takes $>15 \mathrm{yr}$ ) the simulation results remain qualitatively similar (in terms of the relative timing of algal peaks and troughs) but the amplitudes of the diatom and nutrient annuals $c y$ cles are reduced. Simulated diatom and minimum DRSi abundances continue to be broadly consistent with our data, but surface DIN concentrations are persistently too low by a factor of 5 to 10 .
The diatom biomasses at $10 \mathrm{~m}$ depth predicted by the constrained and the unconstrained Lande-Lewis models are visually identical throughout the yeardespite a substantial difference between the mixedlayer average photoadaptive states predicted by the 2 models (data not shown). In contrast, the photoperiod model predicts the late summer diatom recovery to be delayed by approximately 1 mo relative to the all of the remaining models in Years 2 and 3 of the simulation (Fig. 3). During winter the diatom stocks predicted by the photoperiod model are almost 2 orders of magnitude more than those predicted by the Lande-Lewis model. The non-photoadaptive model produces overwinter stocks which are intermediate between those predicted by the Lande-Lewis and photoperiod models, but during the rest of the year it behaves much as the Lande-Lewis model does. There are small differences in the timing of the spring diatom maximum between the Lande-Lewis, non-adaptive, and photoperiod models. The photoperiod model predicts the earliest bloom, whilst the Lande-Lewis model predicts the latest one.

The annual cycle of the compensation depth (the depth at which the population growth rate is zero) has 2 components (Fig. 4). The first is approximately sinusoidal, and reflects the sinusoidal variation in daylength and midday light intensity (and, in the case of the photoperiod model, of the thermocline depth). At the height of summer the compensation depth is predicted to be around $75 \mathrm{~m}$ for the Lande-Lewis, and nonadaptive models and around $67 \mathrm{~m}$ for the photoperiod model. In mid-winter it falls to approximately $55 \mathrm{~m}$ for all of the models. The second component of the annual cycle is a brief suppression of the compensation depth as a consequence of self-shading during the spring bloom.

\section{DISCUSSION}

Comparisons between different models are beset by the problems associated with structural differences between models. We minimised these problems by en-

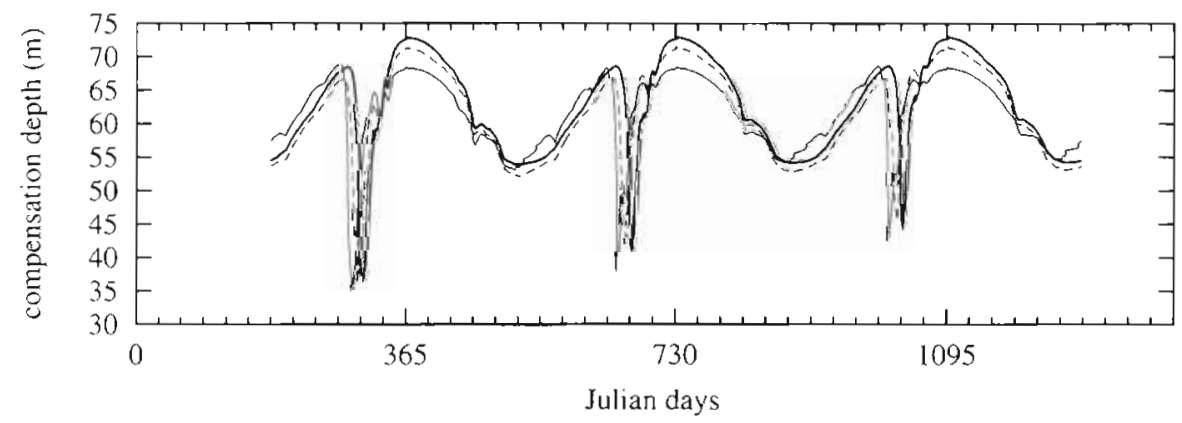

Fig. 4. Simulated compensation depths. Thick line: constrained Lande \& Lewis model; thin line: photoperiod model; dashed line: non-adaptive model 
suring that our model remained structurally and parametrically identical in all aspects except those associated with the photoadaptive response. Here, we have endeavoured to render the comparisons 'fair' by selecting the photoadaptive parameters such that all of the models produce similar annual, mixed-layer average values for the photoadaptive state.

Seasonal shifts in the relative abundances of algal species, with 'dark-adapted' species dominating the phytoplankton in the winter and 'light-adapted' species dominating in the summer, may determine the community-level photoadaptive response. Nonetheless, for each individual species, the 'overwintering problem' remains-particularly in the open ocean where (usually negatively buoyant) cyst formation is less of an option. It is the consequences of species-specific seasonal photoadaptive behaviour which we have been endeavouring to address using hypothetical models. We have ignored diurnal photoadaptation and inter-cellular differences in the photoadaptive state at any given depth. In reality, diurnal photoadaptation may influence the system dynamics (Kamykowsi et al. 1994, Barkmann \& Woods 1996, but see Lande \& Lewis 1989) but we take it as an article of faith that the longer-term consequences of this may be largely 'parameterised out'. Whether or not diurnal photoadaptation can influence day-to-day algal production, it is difficult to argue with the qualitative model that seasonal variations in the pattern of surface irradiance and vertical mixing cause the diurnal mean photoadaptive state of a 'wintertime' alga to be more characteristic of a dark-adapted alga than it would be in a 'summertime' alga. Furthermore, given the short generation time of phytoplankton, seasonally varying selection pressures may also induce seasonal phenotypic changes in the photosynthetic characteristics of an algal population even in the absence of any physiological capacity for an individual cell to photoadapt.

Photoadaptation has little impact upon the surfacelayer algal dynamics during summer. In contrast, during the winter the nature of the photoadaptive response is of prime importance in determining the surface water algal stocks. The photoadaptive state $(\alpha)$ determines the efficiency with which an alga is able to exploit the available PAR. In the fixed $\alpha$ and photoperiod models this efficiency is depth independent (within the mixed layer). In contrast, it is inversely related to depth in the Lande-Lewis model. During the summer, when light is plentiful, mixed-layer production is nutrient limited, and the mixed layer is shallow, this is of little consequence. During the winter, the (large) incremental gain of production in the photoperiod model (relative to that predicted by the LandeLewis model) by that fraction of the population which lies at depths having 'intermediate' light intensities is more than sufficient to offset the (small) production 'loss' from deeper within the mixed layer (where there is insufficient PAR for even the most efficient of algae to fix much carbon). In the photoperiod model, the delayed recovery of the diatom population after the summer crash has a similar explanation: the effective photoperiod is long throughout the (shallow) mixed layer, and hence the efficiency with which algae close to the bottom of the layer can use the relatively low intensities of available PAR is lower than those exhibited by non-adapting, or Lande-Lewis type, algae.

The Lande-Lewis photoadaptive model has a firm empirical basis; however, the photoperiod model is entirely speculative. It is therefore interesting to note that the Lande-Lewis type of response can produce results which are very similar to those of the photoperiod model if convection is assumed to be operating in combination with dispersion. During the winter, and during the summertime night, much of the mixing above the thermocline is convective (with a time scale of a few hours; Large et al. 1994) rather than turbulent. This implies that the light histories of individual cells within and across depth horizons would be more similar than if mixing were purely dispersive. Observed rates of photoadaptation (Cullen \& Lewis 1988) are comparable with or longer than the convective turnover time. Individual cells within the mixed layer will therefore all tend to be photoadapted to the light intensity at the middle of this layer. We developed a fourth model on this premise (cells below the thermocline are assumed to photoadapt to the local light intensity). This model produces results which are very similar to the photoperiod model without any reparameterisation (results not shown).

All of the model variants predict a deep diatom carbon maximum towards the end of the spring bloom. Its location is primarily determined by the location of the thermocline. Nonetheless, it is predicted to occur at a slightly shallower depth in the photoperiod model than in the fixed- $\alpha$ or Lande-Lewis models $(-55$ compared with $\sim 62 \mathrm{~m}$ ). This merely reflects the differing compensation depths predicted by each model (Fig. 4). Furthermore, the shallower summertime compensation depths predicted by the photoperiod model also imply that cells will lose their ability to regulate their buoyancy at a shallower depth in this model than in the remaining models during summer. This will erode the bottom of the subsurface carbon maximum.

Two recent nutrient-phytoplankton models have explictly included a photoadaptive response. Doney et al. (1996) incorporated a state variable representing the chl:N ratio within their model and state that this is necessary in order to produce observed summertime subsurface chlorophyll maxima; however, there is no detailed comparison of the dynamics with and without 
this photoadaptive behaviour. Taylor et al. (1997) developed a nutrient-phytoplankton model which simulates the temporal evolution of the chl: $\mathrm{C}$ ratio (Geider et al. 1997). They found that the peak of the spring bloom was delayed by approximately $10 \mathrm{~d}$ when the algae were forced to maintain a constant chl: $\mathrm{C}$ ratio (cf. an advanced bloom in our model), and that the surface layer biomasses of both chlorophyll and carbon were slightly higher in the non-adaptive model during the late spring to mid-summer period. After this, the biomass of non-adaptive algae falls below that of the adaptive algae. It is not possible to ascertain the magnitude of the difference between the predicted overwintering stocks because these authors present their simulations on linear axes. Summertime DIN depletion is predicted to be less extreme in their model. Taylor et al. (1997) assumed that the percentage of newly dead algal $N$ which passes directly to DIN rises from 30 to $95 \%$ as the DIN concentration declines. Furthermore, the mixed layer is homogenised every night in their model. This enhances the nutrient diffusive flux over the thermocline. They argue that the homogenisation reflects the consequences of convective mixing ${ }_{i}$ however, in our model this is implicitly accounted for in the dispersion coefficient. Since the DIN does not become so depleted in their model, it does not produce the summer 'crash' of diatoms seen in our simulations. Though we have no data for the summer period, the extreme DIN depletion predicted by our model appears unrealistic in comparison with measurements made elsewhere (e.g. Bermuda station; Fasham et al. 1990). The extreme depletion is a robust feature of the model which is most effectively reduced by a large increase in the half-saturation constant for DIN uptake; instantaneous remineralisation of the $\mathrm{N}$ in freshly dead algae increases the summertime, surface-water DIN concentrations only marginally (despite the fact that we adopted a comparatively high weight-specific mortality rate).

The dramatic diatom crash is triggered by the extreme DIN depletion, but its magnitude is undoubtedly also an artefact of our assumption that the algae maintain fixed N:C and Si:C ratios. In a similar model which uses a Lagrangian representation of algal dynamics (Woods \& Onken 1982) and Droop kinetics but lacks any photoadaptive response, the mid-summer diatom population falls to a much more realistic minimum of about $0.1 \mathrm{mg} \mathrm{C} \mathrm{m}{ }^{-3}$ in the surface waters (N. Broekhuizen unpubl.).

Woods \& Barkmann (1993) presented a Lagrangian model of nutrient-diatom dynamics incorporating an (unconstrained) model of the time evolution of the mean photoadaptive state of a population of individuals, but made no reference to field data. The advantage of the Lagrangian approach is that algae within a
Lagrangian cell share a common past trajectory. In general, the variance about the mean photoadaptive state within a Lagrangian cell should be smaller than at a corresponding node in an otherwise similar Eulerian model. Consequently, the resultant population average growth rate (which is a non-linear function of the photadaptive state) should be simulated more accurately (Woods \& Onken 1982). In practice it is not clear whether the 2 schemes produce significantly different results (see Lande \& Lewis 1989, Barkmann \& Woods 1996). The 2 schemes will converge as the extent to which each individual alga can photoadapt becomes increasingly constrained.

Whilst we have sought primarily to determine how different models of seasonal photoadaptation might influence algal dynamics (particularly during the winter period), we have a secondary interest in making quantitative comparisons between model simulations and field data.

The transient year-on-year decline in surface water nutrient concentrations indicates that our initial conditions do not represent the equilibrium dynamics of the model. When the model is run to a stable annual cycle (which takes $>15 \mathrm{yr}$ ), winter diatom densities are predicted to be approximately an order of magnitude lower than those illustrated here; the peaks of the spring blooms occur at very similar times of the year, but are also reduced 5 - to 10 -fold in magnitude. The mid-summer diatom minimum is not quite so extreme, but densities still fall to around $10^{-4} \mathrm{mg} \mathrm{C} \mathrm{m}^{-3}$. DIN is predicted to be too rare in comparison with data throughout the year. Predicted DRSi levels are within the measured range, but the amplitude of the annual cycle is too small. This might suggest that our fitted value for the diatom $\mathrm{Si}$ C ratio is too small, and certainly our value is at the lower end of the range of estimated values. It is possible that the DIN depletion is a consequence of our failure to fully represent heterotrophic activity and other recycling processes, but the DIN pool still declines even if we allow up to $50 \%$ of the algal $\mathrm{N}$ to pass directly into DIN upon death. Other explanations are also possible: our bottom boundary conditions or our vertical mixing coefficients may be at fault; however, both were inferred from field measurements. Alternatively, it may be that in some years the vertical mixing is such that the system runs down whilst it becomes enriched in other years; however, simulations using forcing data for 1994 also run down in a similar manner. Perhaps the most likely explanation is that in reality (cf. in the model) water in the area which we are simulating is advecting eastward slowly. Materials introduced in this water may prevent local nutrient rundown.

We have explicitly considered 3 classes of photoadaptive model. Our results indicate that seasonal pho- 
toadaptation has comparatively little impact upon the surface layer algal dynamics when the mixed layer is shallow and algal production is nutrient limited. When these conditions are not met, photoadaptation can have a very large impact upon surface-layer dynamics. By late winter, algae which photoadapt 'appropriately' may be more than an order of magnitude more abundant than those which do not. Consequently they also bloom 1 to 2 wk earlier. Unfortunately, field data rarely allow late winter algal biomasses, or the timing of the spring bloom, to be identified with a greater degree of certainty than these ranges, and we know of no studies which have tracked the seasonal dynamics of a species-specific photoadaptive state. It is particularly noteworthy that our hypothetical model assumes that algae will tend to be most dark adapted when mixing depths are greatest (i.e. during the cold winter). The C:chl model of Taylor et al. (1997) makes a similar prediction yet laboratory data suggest that when exposed to (unnaturally large) extremes of temperature, algae behave as though adapted to higher light intensities at low temperatures (Geider 1987, Maxwell et al. 1994). The advent of double flash fluorometry technology (Kolber \& Falkowski 1993) will make it possible to make in situ measurements of the photosynthetic characteristics of natural phytoplankton assemblages, and this may enable us to resolve this apparent conflict and progress beyond the largely speculative models presented in this paper to more mechanistic ones.

Acknowledgements. We are grateful to the many people who have contributed to the gathering of the field data which we have presented along with our simulations - notably Drs Julie Hall, Janet Bradford-Grieve and Mark James. This manuscript has benefited greatly from the constructive criticisms of Julie Hall, Kit Rutherford and Graham McBride. Three anonymous referees also provided valuable additional help. N.B. and M.H. were funded through grant number C01623 by the New Zealand Foundation for Research in Science \& Technology. A.H.T. was supported by the NIWA visiting scientist program

\section{LITERATURE CITED}

Anderson L, Sweeney B (1977) Diel changes in the sedimentation characteristics of Ditylum brightwelli, a marine centric diatom: changes in the cellular lipids and effects of respiratory inhibitors and ion-transport modifiers. Limnol Oceanogr 22:539-552

Barkmann W, Woods JD (1996) On using a Lagrangian model to calibrate primary production determined from in vitro incubation measurements. J Plankton Res 18(5):767-788

Bradford-Grieve JM, Chang FH, Gall M, Pickmere $S$, Richards F (1997) Size fractionated phytoplankton standing stocks and primary production during austral winter and spring 1993 in the Subtropical Convergence region near New Zealand. NZ J Mar Freshwat Res 31 (2):201-224

Brzezinski MA (1985) The Si:C:N ratio of marine diatoms: interspecific variability and the effect of some environmental variables. J Phycol 21(3):347-357
Caperon J, Meyer J (1972) Nitrogen-limited growth of marine phytoplankton II. Uptake kinetics and their role in nutrient limited growth of phytoplankton. Deep-Sea Res 19:619-632

Chan AT (1980) Comparative physiological study of marine diatoms and dinoflagellates in relation to irradiance and cell size. I. Growth under continuous light, J Phycol 14: $396-402$

Cullen JJ, Lewis MR (1988) The kinetics of algal photoadaptation in the context of vertical mixing. J Plankton Res 10: $1039-1063$

Doney SC, Gover DM, Najjar RG (1996) A new coupled, onedimensional biological-physical model for the upper ocean: application to the JGOFS Bermuda Atlantic Time-Series Study (BATS) site. Deep-Sea Res II 43(2-3):591-624

Fasham MR, Ducklow HW, McKelvie SM (1990) A nitrogenbased model of plankton dynamics in the oceanic mixed layer. J Mar Res 48:591-639

Fisher T, Minnaard J, Dubinsky Z (1996) Photoacclimation in the marine alga Nannochloropsis sp. (Eustigmatophyte): a kinetic study. J Plankton Res 18(10):1797-1818

Frenette JJ, Demers S, Legendre L, Boulé M (1996) Sizerelated photosynthetic characteristics of phytoplankton during periods of seasonal mixing and stratification in an oligotrophic multibasin lake system. J Plankton Res 18(1): $45-61$

Gaspar P, Gregoris Y, Lefevre JM (1990) A simple eddy kinetic energy model for simulations of the oceanic vertical mixing: tests at station Papa and long-term upper ocean study site. J Geophys Res 95:16179-16193

Geider RJ (1987) Light and temperature dependence of the carbon to chlorophyll $a$ ratio in the microalgae and cyanobacteria: implications for physiology and growth of phytoplankton. New Phytol 106:1-34

Geider RJ, Macintyre H.L, Kana TM (1997) Dynamic model of phytoplankton growth and acclimation: responses of the balanced growth rate and the chlorophyll a:carbon ratio to light, nutrient-limitation and temperature. Mar Ecol Prog Ser 148:187-200

Hadfield MG (1996) A meteorological dataset over the sea near Chatham Island, New Zealand. NZOI Physics Section Report, 1996/3. NIWA, Wellington

Hadfield MG, Sharples J (1996) Modelling mixed layer depth and plankton biomass off the west coast of South Island, New Zealand. J Mar Syst 8:1-29

Howard-Williams C, Davies-Colley R, Vincent W (1995) Optical properties of the coastal and oceanic waters off South Island, New Zealand: regional variation. NZ J Mar Freshwat Res 29(4):589-612

Jerlov NG (1978) Marine optics. Elsevier, Amsterdam

Kamykowski D, Yamazaki H, Janowitz GS (1994) A lagrangian model of phytoplankton photosynthetic response in the upper mixed laver. J Plankton Res 16(8).1059-1069

Kolber Z, Falkowski PG (1993) Use of active fluorescence to estimate phytoplankton photosynthesis in situ. Limnol Oceanogr 38(8): 1646-1665

Lande $R$, Lewis MR (1989) Models of photoadaptation and photosynthesis by algal cells in a turbulent mixed layer. Deep-Sea Res 36(8): 1161-1175

Langdon C (1993) The significance of respiration in production measurements based on oxygen. ICES Mar Sci Symp $167: 69-78$

Large WG, MCWilliams JC, Doney SC (1994) Ocean vertical mixing: a review and a model with a nonlocal boundary layer parameterization. Rev Geophys 32(4):363-403

Levitus S, Conkright ME, Gelfeld RD, Boyer T (1994) World ocean atlas 1994 presents new ocean climatologies. Earth Syst Monitor 5(2):1-2,13-1.4 
Mague TH, Friberg E, Hughes DJ, Morris I (1980) Extracellular release of $C$ by marine phytoplankton: a physiological approach. Limnol Oceanogr 25(2):262-279

Malinski-Rushansky NZ, Legrand C (1996) Excretion of dissolved organic carbon by phytoplankton of different size classes and subsequent bacterial uptake. Mar Ecol Prog Ser 132:249-255

Maxwell DP, Falk S, Trick CG, Hunter NPA (1994) Growth at low temperature mimics high-light acclimation in Chlorella vulgaris. Plant Physiol 105:535-543

McBride GB (1992) Simple calculation of daily photosynthesis by means of five photosynthesis-light equations. Limnol Oceanogr $37(8): 1796-1808$

McBride GB, Vant WN, Cloern JE, Liley JB (1993) Development of a model of phytoplankton blooms in Manukau Harbour. NIWA Ecosystems Publication \#3, Hamilton

Moisan JR, Hofmann EE (1996) Modelling nutrient and plankton processes in the California coastal transition zone 1 A time- and depth-dependent model. J Geophys Res 101(C10):22647-22676

Nelson DM. Tréguer P (1992) Role of silicon as a limiting nutrient to Antarctic diatoms: evidence from kinetic studies in the Ross Sea ice-edge zone. Mar Ecol Prog Ser 80 $255-264$

Paasche E (1973) Silicon and the ecology of marine plankton diatoms. II. Silicate-uptake kinetics in five diatom species. Mar Biol 19:262-269

Pan Y, Subba Rao DV, Mann KH (1996) Acclimation to low light intensity in photosynthesis and growth of Pseudonitzschia multiseries Hasle, a neurotoxigenic diatom. J Plankton Res 18(8):1427-1438

Passow U (1991) Species specific sedimentation and sinking velocities in diatoms. Mar Biol 108:449-455

Reynolds RW, Smith TM (1994) Improved sea surface temperature analyses using optimum interpolation. J Clim 7(6): 929-948

Ross AH, Gurney WSC, Heath MR, Hay SJ, Henderson EW (1993) A strategic simulation model of a fjord ecosystem. Limnol Oceanogr 38(1):128-153

Sakshaug E, Johnsen G, Andresen K, Vernet M (1991) Modelling of light dependent algal photosynthesis and growth experiments with the Barents Sea diatoms Thalassiosira

Editorial responsibility: Otto Kinne (Editor),

Oldendorf/Luhe, Germany nordenskioeldi \& Chaetoceros furcellatus. Deep-Sea Res $38(4): 415-430$

Smayda TJ (1970) The suspension and sinking of phytoplankton in the sea. Oceanogr Mar Biol Annu Rev 8:353-414

Smith EL (1936) Photosynthesis in relation to light and carbon dioxide. Proc Natl Acad Sci USA 22:504-511

Steemann Nielsen E, Jorgensen EG (1968) The adaptation of plankton algae I. General part. Physiol Plant 12:353-370

Taylor A.H, Joint I (1990) A steady-state analysis of the 'microbial loop' in stratified systems. Mar Ecol Prog Ser 59:1-117

Taylor AH, Watson AJ, Ainsworth M, Robertson JE, Turner DR (1991) A modelling investigation of the role of phytoplankton in the balance of carbon at the surface of the North Atlantic. Global Biogeochem Cycles 5(2):151-171

Taylor AH, Geider RJ, Gilbert FJH (1997) Seasonal and latitudinal dependencies of phytoplankton carbon-to-chlorophyll a ratios: the results of a modelling study. Mar Ecol Prog Ser 152:51-66

Tréguer P, Kamatani A, Guenely S, Quéguiner B (1989) Kinetics of dissolution of Antarctic diatom frustules and the biogeochemical cycle of silicon in the Southern Ocean. Polar Biol 9:397-403

Verity PG (1981) Effects of temperature, irradiance, and daylength on the marine diatom Leptocyclindricus danicus Cleve. I. Photosynthesis and cellular composition. J Exp Mar Biol Ecol 55:79-91

Vincent WF, Wake GC, Austin PC, Bradford JM (1989) Modelling the upper limit to oceanic phytoplankton production as a function of latitude in the New Zealand Exclusive Economic Zone. NZ J Mar Freshwat Res 23(3):401-410

Waite AM, Thomson PA, Harrison PJ (1992) Does energy control the sinking rates of marine diatoms? Limnol Oceanogr $37(3): 468-477$

Woods JD, Barkmann W (1993) Diatom demography in winter - simulated by the Lagrangian Ensemble method. Fish Oceanogr 2:202-222

Woods JD, Onken R (1982) Diurnal variation and primary production in the ocean - preliminary results of a Lagrangian ensemble model. J Plankton Res 4(3):735-755

Yentsch CS, Lee RW (1996) A study of the photosynthetic light reactions and a new interpretation of sun and shade phytoplankton. J Mar Res 24:319-337

Submitted: March 24, 1998; Accepted: July 31, 1998 Proofs received from author(s): November 16, 1998 